\title{
Imunidade celular em vacas Holandesas soropositivas para o Vírus da Leucose Bovina (BLV) durante o período de transição
}

\author{
[Cellular immunity in Holstein cows seropositive for Bovine Leukosis Virus (BLV) \\ during the transition period] \\ V. Gomes ${ }^{1}$, V.A.P. Baldacim ${ }^{1}$, J.F.R. Costa ${ }^{1}$, C.P. Costa e Silva ${ }^{1}$, J.R.P. Arcaro ${ }^{2}$, M.S. Miranda ${ }^{2}$, \\ R.S. Sousa ${ }^{1}$, J.J. Fagliari ${ }^{3}$, K.M. Madureira ${ }^{4}$ \\ ${ }^{1}$ Faculdade de Medicina Veterinária e Zootecnia - Universidade de São Paulo - São Paulo, SP \\ ${ }^{2}$ Agência Paulista de Tecnologia dos Agronegócios (Apta) - São Paulo, SP \\ ${ }^{3}$ Faculdade de Ciências Agrárias e Veterinárias - Universidade Estadual Paulista "Júlio de \\ Mesquita Filho" - Jaboticabal, SP \\ ${ }^{4}$ Escola de Medicina Veterinária e Zootecnia - Universidade Federal da Bahia - Salvador, BA
}

\section{RESUMO}

Esta pesquisa avaliou a dinâmica dos leucócitos e das subpopulações de linfócitos em vacas Holandesas soropositivas para o BLV no período de transição. Amostras de sangue $(n=72)$ provenientes de 12 vacas foram coletadas entre as semanas $-2 \mathrm{e}+3$ para a realização do leucograma, imunofenotipagem, dosagem de cortisol e haptoglobina (Hp). O perfil leucocitário foi caracterizado por leucocitose, neutrofilia, monocitose e eosinopenia próximo ao parto. Linfocitose e elevada proporção de linfócitos B CD21 ${ }^{+}$ foram achados constantes entre as semanas -2 e +3 ; assim, as vacas foram testadas e confirmadas soropositivas para o BLV. Os valores das subpopulações de linfócitos T apresentaram-se baixos durante o período de transição, observando-se dois picos máximos que coincidiram com as elevações nas concentrações de cortisol no parto $(2,11 \mu \mathrm{g} / \mathrm{dL})$ e semana $+3(1,97 \mu \mathrm{g} / \mathrm{dL})$. Hp apresentou aumento crescente de $-2(166 \mu \mathrm{g} / \mathrm{mL})$ a $+3(576 \mu \mathrm{g} / \mathrm{mL})$, provavelmente associada à elevada taxa de infecções uterinas observadas nas semanas $+2 \mathrm{e}+3$. As vacas soropositivas para o BLV apresentaram leucograma de estresse próximo ao parto, exceto para linfócitos. A linfocitose e as elevadas proporções de células B $\mathrm{CD} 21^{+}$, associadas com as baixas proporções de células $\mathrm{T}$, podem ser indicativo de imunossupressão e predisposição aos processos inflamatórios no período pós-parto.

Palavras-chave: periparto, haptoglobina, cortisol, subpopulações de linfócitos

\begin{abstract}
This research evaluated the dynamics of leukocytes and lymphocytes subsets in seropositive Holstein cows for BLV during the transition period. Blood samples $(n=72)$ from 12 cows were harvested from week -2 up to week +3 to perform leukogram, immunophenotyping, cortisol and haptoglobin (Hp). Leukocytes pattern was characterized by leukocytosis, neutrophilia, monocytosis and eosinopenia around calving. Lymphocytosis and high proportions of $B$ cells $C D 21^{+}$were a constant finding between week -2 and +3 , thus cows were tested and confirmed seropositive for BLV. The values of T lymphocytes subsets were low during the transition period, observing two peaks that coincided with high levels of cortisol at delivery $(2.11 \mu \mathrm{g} / \mathrm{dL})$ and week $+3(1.97 \mu \mathrm{g} / \mathrm{dL})$. Hp had gradual increase from week $-2(166 \mu \mathrm{g} / \mathrm{mL})$ until week $+3(576 \mathrm{~g} / \mathrm{mL})$ probably due to high rate of uterine infection detected between week +2 and +3 . The seropositive cows for BLV presented stress leukogram around delivery, except for lymphocytes. Lymphocytosis and the high proportions of B cells, associated with the low proportions of $T$ lymphocytes, can be indicative of immunosuppression and predisposition to the inflammatory process observed in the post-partum period.
\end{abstract}

Keywords: peripartum, haptoglobin, cortisol, lymphocytes subsets

Recebido em 17 de março de 2016

Aceito em 21 de fevereiro de 2017

E-mail: viviani.gomes@usp.br 


\section{INTRODUÇÃO}

O crescimento da indústria leiteira nas últimas décadas exigiu a seleção genética por produção, o que resultou em aumento dos requerimentos energéticos. Esse fenômeno é intensificado no período de transição devido à nutrição fetal, colostrogênese e lactogênese (Ingvartsen e Moyes, 2013). O atendimento às demandas energéticas impostas no período de transição é dependente de mecanismos homeostáticos e homeorréticos, regulados pela secreção das catecolaminas, pelo cortisol, pela insulina, pelo glucagon, pelo hormônio do crescimento e pelo hormônio semelhante à insulina do tipo I (Drackley, 1999).

A adaptação metabólica das vacas ocorre em concomitância com uma série de fatores estressantes, incluindo mudanças na dieta, reagrupamentos sociais e alterações físicas, hormonais e fisiológicas associadas ao parto. Esses eventos resultam na liberação do cortisol e em situação de alerta orgânico, no qual as células de defesa são redistribuídas, observando-se o influxo dos neutrófilos e efluxo dos linfócitos dos tecidos para os vasos sanguíneos (Davis et al., 2008). Os glicocorticoides também alteram a transcrição gênica da interleucina 12, que estimula a resposta proliferativa dos linfócitos mediante estímulo antigênico. Esse mecanismo está associado com a diminuição da proporção de linfócitos auxiliares $\left(\mathrm{CD}^{+}\right)$e citotóxicos $\left(\mathrm{CD} 8^{+}\right)$, observados ao redor da parição (Van Kampen e Mallard, 1997; Kimura et al., 2002).

Linfócitos B $\left(\mathrm{CD} 21^{+}\right)$apresentam padrão variável durante o periparto. Foram relatados valores constantes e similares ao período de lactação plena (Van Kampen e Mallard, 1997; Kimura et al., 2002), enquanto outros autores observaram decréscimo na população de células B (Ohtsuka et al., 2010) ou acréscimo (Meglia et al., 2005).

O balanço e a interação entre as diferentes células do sistema imune, especialmente as subpopulações de linfócitos, são fundamentais para a defesa do organismo contra os agentes infecciosos. Alterações nas proporções e migração das subpopulações de linfócitos podem afetar a resposta imune local e a sistêmica (Van Kampen e Mallard, 1997), tornando os animais susceptíveis aos processos inflamatórios pósparto devido à mastite e à metrite.

O desequilíbrio entre as subpopulações de linfócitos sanguíneos em vacas Holandesas, independentemente do ciclo de lactação, pode ser afetado pelo vírus da leucose bovina (BLV). Esse vírus infecta células $B$ e compromete a homeostase das subpopulações de linfócitos pelo desequilíbrio entre a proliferação e a morte celular (Souza et al., 2011). A soroprevalência para o BLV em rebanhos leiteiros, na região Sudeste do Brasil, é de aproximadamente 49,53 79,75\% (Rajão et al., 2014). Apesar da elevada ocorrência, ainda não existem descrições sobre o perfil dos leucócitos sanguíneos em vacas soropositivas para o BLV no período de transição.

A dinâmica e a atividade funcional das células imunes no período de transição possuem destaque na literatura internacional, entretanto pesquisas nacionais que consideram as condições sanitárias de criação brasileiras são escassas e incluem um curto período de avaliação. Assim, o objetivo desta pesquisa foi avaliar a resposta imune celular em vacas Holandesas soropositivas para o BLV durante o período de transição.

\section{MATERIAL E MÉTODOS}

Esta pesquisa foi aprovada pelo Comitê de Ética no Uso de Animais da Faculdade de Medicina Veterinária e Zootecnia da Universidade de São Paulo (Protocolo \#2767/2012).

Este estudo foi conduzido entre setembro e novembro de 2013, em fazenda experimental pertencente à Agência Paulista de Tecnologia dos Agronegócios (Apta), localizada na cidade de Nova Odessa - São Paulo (latitude $22^{\circ} 75^{\prime} \mathrm{S}$ e longitude $\left.47^{\circ} 27^{\prime} \mathrm{W}\right)$. Para tanto, foram selecionadas 12 vacas da raça Holandesa, entre a segunda e a quarta parição, de acordo com a data da inseminação e a previsão de parto.

As condições de manejo adotadas durante o experimento foram conduzidas de acordo com a rotina da fazenda. As vacas foram transferidas para piquete maternidade, composto por capim do gênero Cynodon (coast-cross e tifton), aos 30 dias do parto previsto. Em relação às condições de bem-estar das vacas, observaram-se variações de acordo com as condições climáticas do 
período, considerando-se a ausência de cobertura no piquete maternidade, exceto pela existência de algumas árvores. Não existiam áreas específicas para a parição e os partos não eram assistidos no período noturno.

A composição da dieta oferecida para as vacas no pré e pós-parto era igual (Tab. 1), entretanto as quantidades de silagem de milho (pré-parto: 20kg; pós-parto: $35 \mathrm{~kg}$ ) e concentrado (pré-parto: total equivalente a $3 \mathrm{~kg}$; pós-parto: $1 \mathrm{~kg}$ para cada litro de leite produzido) eram diferentes. A produção de leite diária dos animais variou de 25 a 30 litros entre as semanas $+1 \mathrm{e}+3$. O balanço aniônico da dieta não era considerado, devido à alegação de baixos índices de ocorrência para hipocalcemia e retenção de placenta. Drench pós-parto também não era fornecido.

Tabela 1. Composição da dieta oferecida para as vacas Holandesas no período de transição

\begin{tabular}{lc}
\multicolumn{1}{c}{ Ingredientes } & $\% \mathrm{MS}$ \\
\hline Feno de tifton & 3,00 \\
Silagem de milho & 47,00 \\
Milho moído & 33,00 \\
Farelo de soja 45\% & 14,00 \\
Vitaminas & 2,00 \\
Sal mineral & 1,00 \\
\hline \multicolumn{1}{c}{ Composição química } \\
\hline Matéria seca MS (\%) \\
Proteína bruta - PB (\%) \\
Extrato Etéreo - EE (\%) \\
Extrativo não nitrogenado - ENN (\%) \\
Matéria mineral - MM (\%) \\
Cálcio (g/kg) & $65,5,11$ \\
Fósforo (g/kg) & 6,56 \\
\hline
\end{tabular}

As análises relativas a esta pesquisa foram realizadas entre as semanas -2 e +3 em relação ao parto. A ocorrência das doenças nesse período foi estimada pelos registros da propriedade.
Amostras de sangue $(n=72)$ foram coletadas semanalmente por meio da punção da artéria coccígea em tubos sem e com o anticoagulante Ethylene Diamine Tetraacetic Acid $(1,5 \mathrm{mg} / \mathrm{mL})$. Os tubos sem anticoagulante foram centrifugados a $800 \times$ g por 20 minutos, sendo o soro armazenamento e congelado a $-80^{\circ} \mathrm{C}$.

Leucócitos totais foram determinados por meio de contagem automática (ABX ABC Vet, ABX Diagnostics, Brasil). O exame diferencial dos leucócitos foi realizado por metodologia manual (Birgel, 1982). O fenótipo dos linfócitos sanguíneos foi determinado pela técnica de citometria de fluxo, de acordo com o protocolo descrito por Della Libera et al. (2012). Resumidamente, $100 \mu \mathrm{L}$ de sangue foram lisados, utilizando-se solução salina isotônica $(\mathrm{NaCl}$ $0,2 \%$ e $\mathrm{NaCl} 1,6 \%$ ). Anticorpos (ACs) monoclonais específicos para receptores de superfície dos linfócitos bovinos foram selecionados para a marcação das células (Tab. 2). As células foram incubadas com $100 \mu \mathrm{L}$ de ACs primários previamente diluídos em Phosphate Saline Buffer (PBS), por 30 minutos, a $4^{\circ} \mathrm{C}$. As células foram lavadas $3 \mathrm{x}$ em PBS, sendo posteriormente incubadas com $100 \mu \mathrm{L}$ de ACs secundários, por 30 minutos, a $4{ }^{\circ} \mathrm{C}$, em ambiente escuro. Por fim, as células foram lavadas $2 \mathrm{x}$ e suspensas em $300 \mu \mathrm{L}$ de PBS. A aquisição dos eventos foi realizada em citômetro de fluxo FACS Calibur, por meio do programa CellQuest (Becton Dickinson Immunocytometry System, San Jose, EUA). Os eventos adquiridos (15.000) foram avaliados quanto à emissão das fluorescências no programa FlowJo Software (Tree Star, Ashland, EUA). Os resultados foram expressos na porcentagem de células positivas para cada fluorescência associada aos marcadores de superfície. O valor absoluto das populações de linfócitos foi calculado multiplicando-se a proporção $(\%)$ das populações determinada por citometria de fluxo pelo número de linfócitos totais (células/ $\mu \mathrm{L}$ ).

Tabela 2. Anticorpos (Ac) usados para a marcação dos linfócitos sanguíneos

\begin{tabular}{cccccc}
\hline Ac primário $^{1}$ & Clone & Isotipo & Diluição & Ac secundário $^{2}$ & Diluição $^{+}$ \\
\hline $\mathrm{CD}^{+}$células T & MM1A & IgG1 & $1: 200$ & Pe-Cy5.5 & $1: 400$ \\
$\mathrm{CD} 4^{+}$células T & CACT83B & IgM & $1: 400$ & FITC & $1: 400$ \\
$\mathrm{CD}^{+}$células T & BAQ111A & IgM & $1: 200$ & FITC & $1: 100$ \\
$\mathrm{CD} 21^{+}$células B & BAQ15A & IgM & $1: 200$ & FITC & $1: 200$ \\
\hline
\end{tabular}

${ }^{1}$ Ac monoclonal primário antibovino gerado em camundongos (VMRD, Pullman, EUA)

${ }^{2} \mathrm{Ac}$ monoclonal secundário anticamundongo gerado em caprinos (Life Technologies, Carlsbad, EUA). 
As amostras de soro foram submetidas ao teste imunoenzimático para detecção de anticorpos específicos para a glicoproteína gp 51 do BLV (De Giuseppe et al., 2004).

A haptoglobina foi determinada pela separação eletroforética do soro em gel de poliacrilamida SDS-PAGE (Dodecil-Sulfato de Dódio de Poliacrilamida), de acordo com o proposto por Laemmli (1970). Após a separação das frações proteicas, o gel foi corado com azul de Coomassie a 0,2\%. As concentrações das proteínas foram determinadas por densitometria computadorizada (Shimadzu CS9301, Tokyo, Japão).

A concentração de cortisol foi determinada por ensaio quimiluminescente, utilizando-se kit comercial em analisador de imunoensaios Immulite $1000^{\circledR}$ (Siemens, Brasil), de acordo com as instruções do fabricante. O kit comercial detecta concentrações de cortisol $\geq 1,0 \mu \mathrm{g} / \mathrm{dL}$.

A análise estatística foi realizada utilizando-se o programa estatístico SPSS 17.0 (IBM Corporation, Armonk, Nova York). As variáveis não apresentaram distribuição normal pelo teste de Shapiro-Wilk. A análise no tempo foi realizada por meio do teste de Friedman $(\mathrm{P} \leq 0,05)$. A este último teste, quando apresentou pelo menos um tempo significativamente diferente, foram realizadas as comparações múltiplas por meio do teste de Wilcoxon com correção de Bonferroni $(\mathrm{P} \leq 0,0033)$. Tendência estatística foi considerada quando o $\mathrm{P}<0,0066$. Devido ao elevado número de amostras negativas ao cortisol, optou-se pela apresentação descritiva dos dados em mediana, valores mínimos e máximos.

\section{RESULTADOS}

As doenças relatadas entre a parição (semana 0) e a semana +3 foram distocia $(33,4 \%, 4 / 12)$, retenção de placenta $(8,3 \%, 1 / 12)$, hipocalcemia clínica $(8,3 \%, 1 / 12)$, cetose clínica $(8,3 \%, 1 / 12)$ e metrite $(41,7 \%, 5 / 12)$. Duas das quatro vacas com episódios de distocia também apresentaram cetose, e do total de animais que apresentaram metrite, três já haviam desenvolvido distúrbios prévios: duas vacas com distocia e uma com retenção de placenta. Além disso, as 12 vacas desta pesquisa $(12 / 12,100 \%)$ apresentaram reações positivas ao teste imunoenzimático para anticorpos específicos contra o antígeno gp51 do BLV, entretanto nenhuma das vacas apresentava a forma tumoral da doença.

Os valores absolutos e relativos dos leucócitos sanguíneos em vacas Holandesas durante o período de transição estão expressos na Tab. 3 . Os leucócitos totais aumentaram gradualmente da semana -2 até a parição, observando-se queda brusca no período pós-parto. Neutrófilos e monócitos apresentaram variações similares aos leucócitos totais. Os valores absolutos de linfócitos aumentaram progressivamente entre as semanas -2 e +1 , seguidos por diminuição gradual nas semanas +2 e +3 . Os eosinófilos diminuíram gradualmente do pré-parto até a semana +1 , observando-se ligeiro aumento nas semanas +2 e +3 . Basófilos foram detectados apenas nas semanas $+1 \mathrm{e}+2$.

Todos os componentes do leucograma apresentaram variações durante o período de transição, segundo o teste de Friedman $(\mathrm{P} \leq 0,05)$, com exceção do número absoluto de linfócitos $(\mathrm{P}=0,587)$ e basófilos $(\mathrm{P}=0,756)$. A comparação múltipla pelo teste de Wilcoxon com correção de Bonferroni identificou apenas tendências estatísticas entre o dia da parição e a semana -2 $(\mathrm{P}=0,006)$ e entre as semanas $-1(\mathrm{P}=0,006)$ e +3 $(\mathrm{P}=0,006)$ para os leucócitos totais; entre as semanas 0 e $-1 \quad(\mathrm{P}=0,005)$ para os valores relativos de eosinófilos; entre as semanas +1 e -2 para os valores absolutos de eosinófilos $(\mathrm{P}=0,004)$; e entre as semanas $0 \mathrm{e}+2$ para os valores absolutos $(\mathrm{P}=0,004)$ de monócitos.

Os valores medianos absolutos e relativos das populações de linfócitos estão apresentadas na Tab. 4. Os valores medianos para os linfócitos $\left(\mathrm{CD}^{+}\right)$aumentaram da semana -2 ao parto, observando-se diminuição nos momentos subsequentes. Apesar das variações observadas, não foi possível detectar diferenças no tempo para $\mathrm{CD}^{+}(\mathrm{P} \geq 0,05)$. Os valores relativos $(\%) \mathrm{e}$ absolutos $\left(\times 10^{3}\right.$ cells $\left./ \mu \mathrm{L}\right)$ para o linfócito $\mathrm{T}$ auxiliar $\left(\mathrm{CD}^{+} \mathrm{CD}^{+}\right)$diminuíram entre as semanas -2 e -1 , observando-se picos máximos ao redor da parição e nas semanas +2 e +3 . Foi possível detectar variações no tempo para as proporções de $\mathrm{CD}^{+} \mathrm{CD}^{+}(\mathrm{P}=0,029)$, entretanto a comparação múltipla entre os tempos apresentou $\mathrm{P} \geq 0,003$. Os valores absolutos de $\mathrm{T}$ citotóxicos $\left(\mathrm{CD}^{+} \mathrm{CD}^{+}\right)$ aumentaram progressivamente do período 
pré-parto ao parto, observando-se diminuição dos valores no período pós-parto. Os valores relativos para $\mathrm{T}$ citotóxico também aumentaram da semana -2 ao parto, em seguida, as proporções celulares diminuíram na semana +1 , observandose pico máximo nas semanas +2 e +3 . Foi possível identificar variações no tempo para as proporções de $\mathrm{CD}^{+} \mathrm{CD}^{+}(\mathrm{P}=0,016)$, entretanto a comparação múltipla entre os tempos apresentou $\mathrm{P} \geq 0,003$.

Os valores relativos e absolutos para células B $\mathrm{CD} 21^{+}$foram relativamente estáveis durante o período de transição. Não foi possível detectar diferenças entre os momentos para células $\mathrm{CD} 21^{+}(\mathrm{P} \geq 0,05)$.
Os valores medianos obtidos para a $\mathrm{Hp}$ foram de 166 (43-149), 198 (109-508), 320 (180-6780), 457 (286-1145), 609 (160-1009) e 576 (251-940) $\mu \mathrm{g} / \mathrm{mL}$, respectivamente, entre as semanas $-2 \mathrm{e}$ $+3(\mathrm{P}=0,000)$. As comparações múltiplas entre os momentos revelaram que os valores obtidos na semana +1 eram diferentes daqueles obtidos nas semanas -1 e $+3(\mathrm{P} \leq 0,0033)$. As frequências de vacas com concentração de haptoglobina moderada $(8,5$ - $458 \mu \mathrm{g} / \mathrm{mL})$ e alta $(459$ $1757 \mu \mathrm{g} / \mathrm{mL}$ ) eram de 100 e $0 \%$; 91,67 e $8,33 \%$; 81,82 e $18,18 \% ; 58,33$ e $41,67 \% ; 41,66$ e $58,34 \%$; 33,33 e $66,67 \%$ entre as semanas -2 e +3 , respectivamente. As vacas não apresentaram baixas concentrações de haptoglobina $(\leq 8,4 \mu \mathrm{g} / \mathrm{mL})$ ao longo deste estudo (Nightingale et al., 2015).

Tabela 3. Números relativo $(\%)$ e absoluto $\left(\times 10^{3}\right.$ céls./ $\left.\mu \mathrm{L}\right)$ dos tipos leucocitários sanguíneos em vacas Holandesas no período de transição

\begin{tabular}{|c|c|c|c|c|c|c|c|c|}
\hline Células & Variáveis & -2 & -1 & Parto & +1 & +2 & +3 & $\mathrm{Sig}^{*}$ \\
\hline & Mediana & 11,6 & 13,0 & 21,9 & 11,9 & 10,7 & 12,1 & \multirow{3}{*}{0,006} \\
\hline \multirow[t]{3}{*}{ Leucócitos (x10³ céls./ $\mu \mathrm{L})$} & Mínimo & 6,1 & 7,8 & 10,2 & 5,3 & 7,0 & 7,6 & \\
\hline & Máximo & 30,8 & 37,1 & 54,4 & 27,1 & 37,6 & 35,0 & \\
\hline & Mediana & 3,95 & 4,78 & 7,80 & 2,46 & 2,59 & 3,35 & \multirow{3}{*}{0,003} \\
\hline \multirow[t]{3}{*}{ 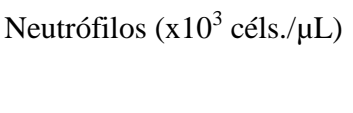 } & Mínimo & 1,33 & 1,87 & 0 & 0,22 & 0,44 & 0,38 & \\
\hline & Máximo & 5,93 & 7,17 & 31,55 & 9,15 & 16,86 & 5,60 & \\
\hline & Mediana & 34,5 & 28,0 & 37,5 & 21,5 & 25,5 & 28,5 & \multirow{3}{*}{0,015} \\
\hline \multirow[t]{3}{*}{ Neutrófilos (\%) } & Mínimo & 11 & 13 & 18 & 2 & 6 & 4 & \\
\hline & Máximo & 48 & 56 & 67 & 69 & 77 & 40 & \\
\hline & Mediana & 0,92 & 0,99 & 0,31 & 0,22 & 0,33 & 0,52 & \multirow{4}{*}{0,038} \\
\hline \multirow[t]{3}{*}{ 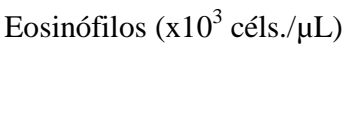 } & Mínimo & 0 & 0,36 & 0 & 0 & 0 & 0,09 & \\
\hline & Máximo & 1,99 & 2,04 & 1,32 & 1,41 & 1,54 & 3,06 & \\
\hline & Mediana & 5,5 & 6,5 & 1,0 & 2,0 & 2,0 & 3,5 & \\
\hline \multirow[t]{2}{*}{ Eosinófilos (\%) } & Mínimo & 0 & 3 & 0 & 0 & 0 & 0,1 & \multirow[t]{2}{*}{0,010} \\
\hline & Máximo & 19 & 10 & 9 & 22 & 18 & 21 & \\
\hline \multirow{3}{*}{ 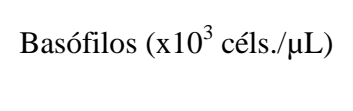 } & Mediana & 0 & 0 & 0 & 0,10 & 0,07 & 0,04 & \multirow{3}{*}{0,756} \\
\hline & Mínimo & 0 & 0 & 0 & 0 & 0 & 0 & \\
\hline & Máximo & 0,13 & 0,24 & 0,44 & 0,13 & 0,37 & 0,17 & \\
\hline \multirow{4}{*}{ Basófilos (\%) } & Mediana & 0 & 0 & 0 & 1,0 & 0,5 & 0 & \multirow{3}{*}{0,718} \\
\hline & Mínimo & 0 & 0 & 0 & 0 & 0 & 0 & \\
\hline & Máximo & 1 & 2 & 2 & 2 & 1 & 2 & \\
\hline & Mediana & 0,18 & 0,38 & 0,44 & 0,03 & 0,00 & 0,04 & \multirow{3}{*}{0,000} \\
\hline \multirow[t]{2}{*}{ Monócitos (x10 $30^{3}$ céls. $/ \mu \mathrm{L}$ ) } & Mínimo & 0 & 0 & 0 & 0 & 0 & 0 & \\
\hline & Máximo & 0,896 & 1,855 & 2,176 & 0,762 & 0,219 & 0,484 & \\
\hline \multirow{3}{*}{ Monócitos (\%) } & Mediana & 1,0 & 3,0 & 2,0 & 0,5 & 0 & 0 & \multirow{3}{*}{0,004} \\
\hline & Mínimo & 0 & 0 & 1 & 0 & 0 & 0 & \\
\hline & Máximo & 7 & 6 & 4 & 6 & 3 & 4 & \\
\hline \multirow{3}{*}{ 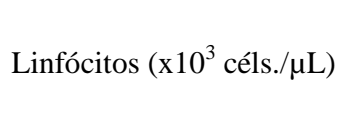 } & Mediana & 6,64 & 7,15 & 7,85 & 8,02 & 6,47 & 6,78 & \multirow{3}{*}{0,587} \\
\hline & Mínimo & 3,05 & 4,10 & 0 & 2,65 & 4,76 & 5,17 & \\
\hline & Máximo & 22,88 & 27,10 & 26,71 & 32,30 & 24,66 & 27,55 & \\
\hline \multirow{3}{*}{ Linfócitos (\%) } & Mediana & 53,5 & 60,0 & 56,5 & 75,0 & 67,0 & 63,0 & \multirow{3}{*}{0,021} \\
\hline & Mínimo & 42 & 32 & 28 & 29 & 23 & 44 & \\
\hline & Máximo & 88 & 78 & 77 & 94 & 91 & 88 & \\
\hline
\end{tabular}

"Diferenças estatísticas pelo teste de Friedman $(\mathrm{P} \leq 0,05)$. 
As concentrações séricas do cortisol $\geq 1,0 \mu \mathrm{g} / \mathrm{dL}$ foram observadas em $25 \%$ (3/12) das vacas entre as semanas -2 e -1 , entretanto o número de animais com valores acima do ponto de detecção aumentou na parição $(11 / 12,91,7 \%)$. No período pós-parto, a frequência de animais positivos diminuiu para 41,7\% (5/12); 33,3\% (4/12) e
$58,3 \%(7 / 12)$ da semana +1 para a +3 , respectivamente. As medianas entre as amostras de cortisol com valores acima de $1,0 \mu \mathrm{g} / \mathrm{dL}$ foram de $1,07(\leq 1,0-1,25) ; 1,06(\leq 1,0-2,72) ; 2,11(\leq 1,0$ $4,27)$; $1,45(\leq 1,0-3,81) ; 1,53(\leq 1,0-2,57) ; 1,97$ $(\leq 1,0-2,85) \mu \mathrm{g} / \mathrm{dL}$ entre as semanas -2 e +3 , respectivamente.

Tabela 4. Valores relativos $(\%)$ e absolutos $\left(\mathrm{x} 10^{3}\right.$ céls./ $\left.\mu \mathrm{L}\right)$ das populações de linfócitos, determinados por citometria de fluxo, em amostras de sangue provenientes de 12 vacas Holandesas no período de transição

\begin{tabular}{|c|c|c|c|c|c|c|c|c|}
\hline Populações & Variáveis & -2 & -1 & Parto & +1 & +2 & +3 & Sig $^{*}$ \\
\hline \multirow{3}{*}{$\begin{array}{c}\mathrm{CD}^{+} \\
\left(\times 10^{3} \text { céls. } / \mu \mathrm{L}\right)\end{array}$} & Mediana & 2,67 & 2,83 & 4,06 & 3,02 & 2,97 & 3,05 & \multirow{3}{*}{0,787} \\
\hline & Mínimo & 1,90 & 1,94 & 2,12 & 0,23 & 0,36 & 1,07 & \\
\hline & Máximo & 6,87 & 7,14 & 11,21 & 6,16 & 5,29 & 7,08 & \\
\hline \multirow{3}{*}{$\begin{array}{c}\mathrm{CD}^{+} \\
(\%)\end{array}$} & Mediana & 36,7 & 37,5 & 43,4 & 38,5 & 33,1 & 39,2 & \multirow{3}{*}{0,889} \\
\hline & Mínimo & 20,5 & 20,0 & 19,9 & 3,6 & 5,6 & 18,0 & \\
\hline & Máximo & 61,5 & 61,0 & 55,8 & 60,1 & 56,8 & 57,9 & \\
\hline \multirow{3}{*}{$\begin{array}{c}\mathrm{CD}^{+} \mathrm{CD}^{+} \\
\left(\mathrm{x} 10^{3} \text { céls. } / \mu \mathrm{L}\right)\end{array}$} & Mediana & 0,60 & 0,40 & 0,97 & 0,60 & 0,83 & 0,95 & \multirow{3}{*}{0,203} \\
\hline & Mínimo & 0,18 & 0,38 & 0,29 & 0,10 & 0,27 & 0,34 & \\
\hline & Máximo & 1,12 & 1,42 & 2,27 & 1,05 & 1,55 & 1,72 & \\
\hline \multirow{3}{*}{$\begin{array}{c}\mathrm{CD}^{+}{ }^{+} \mathrm{CD} 4^{+} \\
(\%)\end{array}$} & Mediana & 7,0 & 4,4 & 9,0 & 5,6 & 10,2 & 11,0 & \multirow{3}{*}{0,029} \\
\hline & Mínimo & 1,2 & 0,5 & 3,4 & 3,2 & 3,8 & 5,6 & \\
\hline & Máximo & 16,1 & 17,0 & 16,4 & 17,4 & 20,3 & 24,3 & \\
\hline \multirow{3}{*}{$\begin{array}{c}\mathrm{CD}^{+}{ }^{+} \mathrm{CD}^{+} \\
\left(\times 10^{3} \text { céls. } / \mu \mathrm{L}\right)\end{array}$} & Mediana & 0,68 & 0,71 & 1,08 & 0,73 & 0,77 & 0,79 & \multirow{3}{*}{0,335} \\
\hline & Mínimo & 0,30 & 0,36 & 0,21 & 0,17 & 0,41 & 0,44 & \\
\hline & Máximo & 1,69 & 1,90 & 4,77 & 1,80 & 3,02 & 1,89 & \\
\hline \multirow{3}{*}{$\begin{array}{c}\mathrm{CD}^{+} \mathrm{CD}^{+} \\
(\%)\end{array}$} & Mediana & 7,2 & 9,0 & 9,3 & 8,4 & 10,6 & 8,4 & \multirow{3}{*}{0,016} \\
\hline & Mínimo & 4,6 & 6,2 & 4,7 & 4,8 & 7,6 & 4,8 & \\
\hline & Máximo & 16,8 & 17,4 & 23,7 & 23,3 & 18,1 & 26,0 & \\
\hline \multirow{3}{*}{$\begin{array}{c}\mathrm{CD}^{2} 1^{+} \\
\left(\mathrm{x} 10^{3} \text { céls. } / \mu \mathrm{L}\right)\end{array}$} & Mediana & 3,54 & 3,33 & 3,85 & 2,92 & 3,79 & 3.49 & \multirow{3}{*}{0,098} \\
\hline & Mínimo & 0,91 & 1,20 & 1,41 & 0,78 & 0,73 & 2,14 & \\
\hline & Máximo & 2,36 & 1,58 & 2,75 & 1,10 & 2,33 & 2,49 & \\
\hline \multirow{3}{*}{$\begin{array}{c}\mathrm{CD} 21^{+} \\
(\%)\end{array}$} & Mediana & 50,3 & 41,3 & 46,0 & 46,7 & 63,6 & 55,2 & \multirow{3}{*}{0,152} \\
\hline & Mínimo & 15,5 & 24,4 & 19,9 & 18,8 & 14,5 & 39,5 & \\
\hline & Máximo & 87,1 & 59,2 & 85,2 & 89,7 & 84,7 & 87,8 & \\
\hline
\end{tabular}

*Diferenças estatísticas pelo teste de Friedman $(\mathrm{P} \leq 0,05)$.

\section{DISCUSSÃO}

O período de transição é marcado por uma série de eventos, como a gestação, o parto, a colostrogênese e a lactogênese, que requerem uma série de adaptações metabólicas para o suprimento dessas demandas fisiológicas. A adaptação das vacas pode ser favorecida pelas condições de criação, caso contrário o desequilíbrio entre a demanda e o consumo pode resultar em cetose e hipocalcemia, estritamente relacionadas à intensificação da imunossupressão relatada para vacas no período de transição. A análise das condições oferecidas às vacas no préparto permitiu identificar alguns fatores de risco que podem ter contribuído para a elevada taxa de doenças no rebanho, tais como: 1 . bem estar - esta pesquisa foi conduzida em meses quentes do ano (primavera e verão), entretanto a área de sombreamento no piquete pré-parto era escassa; além disso, não havia manejo ou área específica que proporcionassem condições favoráveis à privacidade e ao conforto das vacas durante o trabalho de parto. Os partos das vacas não eram assistidos no período noturno e nos finais de semana, propiciando demora na assistência obstétrica dos casos de distocia. Esses eventos, por si só, podem ter intensificado o estresse das vacas ao redor da parição e justificam o pico de cortisol observado nesse período; 2 . em relação à dieta das vacas, pode-se dizer que a relação cálcio e fósforo está desequilibrada (1:2), sendo este um dos fatores que podem ter contribuído para a ocorrência de hipocalcemia clínica. Dados 
a respeito da concentração de cálcio dessas vacas foram apresentados previamente por Baldacim (2014), observando-se hipocalcemia subclínica ao redor de $70 \%$ das vacas na parição e na semana +1 . Assim, os fatores de risco presentes no sistema de criação das vacas contribuíram para a elevada taxa de ocorrência de doenças observada a partir da parição.

Corassin et al. (2011) verificaram incidência de hipocalcemia e metrite de $1,7 \%$ e $19,5 \%$, respectivamente, enquanto, na presente pesquisa, as taxas foram de 8,3 e 41,7\% para as mesmas enfermidades. Esses autores observaram ainda que vacas com retenção de placenta tiveram 3,68 vezes mais chance de apresentarem metrite. No presente estudo, essa relação também existiu: das cinco vacas que apresentaram metrite, três manifestaram doenças prévias, como distocia e retenção de placenta.

Diante do perfil sanitário apresentado pelas vacas, pode-se prever que a dinâmica celular observada ao longo do período de transição foi influenciada por uma série de eventos interconectados: estresse ao redor da parição (pico de cortisol), elevada taxa de doenças a partir da parição e soropositividade das vacas ao BLV.

O pico de cortisol ao redor da parição coincidiu com algumas alterações no leucograma compatíveis com o estresse, exceto para linfócitos (Meglia et al., 2001). O principal evento associado à imunossupressão das vacas ao redor da parição é o efeito negativo do cortisol sobre as subpopulações de linfócitos. Geralmente, observa-se linfopenia decorrente da diminuição da resposta proliferativa, especialmente dos linfócitos $\mathrm{T} \mathrm{CD}^{+}$, diante dos antígenos (Van Kampen e Mallard, 1997; Kimura et al., 2002). Esse perfil foi totalmente alterado nesta pesquisa devido à soropositividade das vacas ao BLV, observando-se linfocitose em razão da elevada proporção de células $\mathrm{B} C D 21^{+}$.

O número de linfócitos observado ao redor da parição nas vacas desta pesquisa foi três vezes maior que aqueles relatados para vacas saudáveis $\left(3,58 \times 10^{3}\right.$ células $\left./ \mu \mathrm{L}\right)$ e semelhante ao valores observados em vacas soropositivas $\left(9,16 \times 10^{3}\right.$ células $\left./ \mu \mathrm{L}\right)$ por Kaczmarczyk et al. (2004). As proporções de células CD21 ${ }^{+}(41,3-$ $63,6 \%)$ aqui obtidas foram semelhantes à proporção de $58 \%$ relatada para vacas lactantes e soropositivas para o BLV (Lewin et al., 1988). Esses valores são superiores às proporções de 24,$1 ; 28,9$ e $22,8 \%$ encontradas nas semanas -3 , parto e +3 por Van Kampen e Mallard (1997), em animais não investigados para BLV. As vacas soropositivas para o BLV apresentam aumento da meia-vida dos linfócitos $\mathrm{B}$ devido à diminuição da taxa de apoptose (Souza et al., 2011), entretanto alguns mecanismos efetores da resposta imune envolvendo as células B estarão suprimidos, justificando, assim, a linfocitose como compensatória. Droogmans et al. (1994) encontraram baixa expressão do receptor da interleucina 6 nas células B infectadas pelo BLV. Essa citocina é fundamental para a diferenciação das células B em plasmócitos produtores de anticorpos.

As proporções de linfócitos $\mathrm{T}$ auxiliares (4,4$11 \%$ ) encontrados nesta pesquisa foram muito menores que os intervalos de 24,8-29,8 e 20,1$38,7 \%$ relatados por Kimura et al. (2002) e Van Kampen e Mallard (1997), respectivamente. Em contrapartida, as proporções de linfócitos $\mathrm{T}$ citotóxicos $(7,2-10,6 \%)$ foram semelhantes àqueles relatados por Kimura et al. (2002) (8,612,3\%) e Van Kampen e Mallard (1997) (5,8$11,5 \%)$. A baixa proporção das subpopulações de linfócitos $\mathrm{T}$ pode ser consequência da menor resposta proliferativa dessas células durante o período de transição sob o efeito de elevadas concentrações de cortisol (Kimura et al., 2002) ou de desequilíbrio na produção de citocinas devido à influência do BLV (Droogmans et al., 1994). Os dados encontrados nesta pesquisa concordam parcialmente com aqueles relatados por Della Libera et al. (2012), que também encontraram maior proporção de células B $\mathrm{CD}_{21}{ }^{+}(41,82 \%)$ e baixas proporções de linfócitos auxiliares $(3,95 \%)$ em vacas soropositivas para o BLV que apresentavam linfocitose persistente, porém esses autores também relataram menores proporções de $\mathrm{T}$ citotóxicos $(6,47 \%)$.

A análise das proporções das subpopulações de células $\mathrm{T}$ no tempo estudado revelou dois picos para as células $\mathrm{CD}^{+} \mathrm{CD}^{+}{ }^{+} \mathrm{CD}^{+} \mathrm{CD} 8^{+}$ao redor da parição e entre as semanas +2 e +3 . Provavelmente as oscilações observadas decorreram de processos inflamatórios causados pelas doenças relatadas nesta pesquisa e/ou por outras doenças infecciosas. Não houve descrição 
de mastite clínica nas fichas de controle sanitário da fazenda, porém tal doença não foi investigada. O segundo pico das subpopulações de linfócitos T no pós-parto provavelmente está associado aos episódios de metrite $(41,7 \%)$.

O aumento da Hp foi gradual da semana -2 à +3 , indicando o agravamento da condição patológica do útero das vacas ao longo do estudo. Nightingale et al. (2015) determinaram as concentrações de haptoglobina em vacas sadias no período de transição e as classificaram conforme o valor encontrado em três grupos distintos: low cows, para valores séricos de $\mathrm{Hp}$ abaixo de $84 \mu \mathrm{g} / \mathrm{mL}$; moderate cows, para valores obtidos entre 85 e $458 \mu \mathrm{g} / \mathrm{mL}$; e high cows, para valores entre 459 e $1.757 \mu \mathrm{g} / \mathrm{mL}$. Considerandose os limiares descritos por esses autores, as vacas desta pesquisa pertenceriam ao grupo moderate cows no pré-parto e ao grupo high cows no pós-parto. A resposta imunológica intensa, porém ineficiente, ao BLV promove a alteração no padrão de expressão das citocinas TNF- $\alpha$, IFN- $\gamma$, L-2, IL-4, IL-6, IL-10 e IL-12 em vacas soropositivas (Amills et al., 2004), a qual, aliada às doenças da produção ocorridas no período, justifica a classificação das vacas analisadas nos perfis estabelecidos pelos autores.

Em geral, o perfil de leucócitos e de subpopulações de linfócitos apresentado pelas vacas no período de transição sofreu influência de fatores fisiológicos relacionados à elevada taxa de cortisol ao redor da parição associada ao BLV e às doenças da produção.

\section{CONCLUSÕES}

O perfil leucocitário apresentado pelas vacas Holandesas ao redor da parição foi compatível com as elevadas concentrações de cortisol, exceto para linfócitos. A dinâmica das subpopulações de linfócitos B foi compatível com a infecção pelo BLV. As subpopulações de linfócitos $\mathrm{T}$ auxiliar e citotóxico foram influenciadas quantitativamente pelo BLV e pelo cortisol, porém as oscilações (picos) observadas foram concomitantes às doenças da produção. Acredita-se que o BLV pode ter sido um dos fatores de risco para a elevada taxa de doenças observadas nas vacas deste estudo.

\section{AGRADECIMENTOS}

Esta pesquisa foi financiada pelo $\mathrm{CNPq}$, projeto número 479381/2013.

\section{REFERÊNCIAS}

AMILLS, M.; NORIMINE, J.; OLMSTEAD, C.A. et al. Cytokine mRNA expression in B cells from bovine leukemia virus-infected cattle with persistent lymphocytosis. Cytokine, v.28, p.25$28,2004$.

BALDACIM, V.A.P. Metabolismo e resposta immune celular no sangue de vacas Holandesas no período de transição. 2014. 107 f. Dissertação (Mestrado em Clínica Veterinária) - Faculdade de Medicina Veterinária e Zootecnia, Universidade de São Paulo, São Paulo, SP.

BIRGEL, E.H. Hematologia clínica veterinária. In: BIRGEL, E.H.; LARSSON, M.H.M.A; HAGIWARA, M.K. et al. (Eds.). Patologia clínica veterinária. São Paulo: Sociedade Paulista de Medicina Veterinária, 1982. p.2-49.

CORASSIN, C.H.; MACHADO, P.F.; COLDEBELLA, A. et al. Importância das desordens do periparto e seus fatores de risco sobre a produção de leite de vacas Holandesas. Semin. Cienc. Agrar., v.32, p.1101-1110, 2011.

DAVIS, A.K.; MANEY, D.L.; MAERZ, J.C. The use of leukocyte profiles to measure stress in vertebrates: a review for ecologists. Funct. Ecol., v.22, p.760-772, 2008.

DE GIUSEPPE, A.; FELIZIANI, F.; RUTILI, D. et al. Expression of the bovine leukemia virus envelope glycoprotein (gp51) by recombinant baculovirus and its use in an enzyme-linked immunosorbent assay. Clin. Diagn. Lab. Immunol., v.11, p.147-151, 2004.

DELLA LIBERA, A.M.M.P.; BLAGITZ, M.G.; BATISTA, C.F. et al. Quantification of B cells and $\mathrm{T}$ lymphocyte subsets in bovine leukemia virus infected dairy cows. Semin. Cienc. Agrar., v.33, p.1487-1494, 2012.

DRACKLEY, J.K. Biology of dairy cows during the transition period: the final frontier. J. Dairy Sci., v.82, p.2259-2273, 1999. 
DROOGMANS, L.; CLUDTS, I.; CLEUTER, Y. et al. Expression of Interleukin 6 receptors and Interleukin 6 mRNA by bovine Leukaemia virusinduced tumour cells. Cytokine, v.6, p.641-646, 1994.

INGVARTSEN, K.L.; MOYES, K. Nutrition, immune function and health of dairy cattle. Animal, v.7, p.112-122, 2013.

KACZMARCZYLK, E.; BOJAROJCNOSOWICZ, B.; FIEDOROWICZ, A. et al. Polymorphism of blood leukocyte acid phosphatase and the profile of peripheral blood lymphocytes in the first lactation trimester of cows naturally-infected with bovine leukaemia virus. Arch. Tierz., v.47, p.415-430, 2004.

KIMURA, K.; GOFF, J.P.; KEHRLI M.E. et al. Effects of mastectomy on composition of peripheral blood mononuclear cell populations in periparturient dairy cows. J. Dairy Sci., v.85, p.1437-1444, 2002.

LAEMMLI, U.K. Cleavage of structural proteins during the assembly of the head of bacteriophage T4. Nature, v.227, p.680-685, 1970.

LEWIN, H.A.; WU, M.C.; NOLAN, T.J. et al. Peripheral B lymphocyte percentage as an Indicator of Subclinical Progression of Bovine Leukemia Virus. J. Dairy Sci., v.71, p.25262534, 1988.

MEGLIA, G.E.; JOHANNISSON, A.; AGENÄS, S. et al. Effects of feeding intensity during the dry period on leukocyte and lymphocyte sub-populations, neutrophil function and health in periparturient dairy cows. Vet. J., v.169, p.376-384, 2005.
MEGLIA, G.E.; JOHANNISSON, A.; PETERSSON, L. et al. Changes in some blood micronutrients, leukocytes and neutrophil expression of adhesion molecules in periparturient dairy cows. Acta Vet. Scand., v.42, p.139-150, 2001.

NIGHTINGALE， C.R.; SELLERS， M.D.; BALLOU, M.A. Elevated plasma haptoglobin concentrations following parturition are associated with elevated leukocyte responses and decreased subsequent reproductive efficiency in multiparous Holstein dairy cows. Vet. Immunol. Immunopathol., v.164, p.16-23, 2015.

OHTSUKA, H.; TERASAWA, S.; WATANABE, C. et al. Effect of parity on lymphocytes in peripheral blood and colostrum of healthy Holstein dairy cows. Can. J. Vet. Res., v.74, p.130-135, 2010.

RAJÃO, D.S.; HEINEMANN, M.B.; REIS, J.K.P. et al. Effects of bovine leukemia virus infection on crossbred and pubebred dairy cattle productive performance in Brazil. Semin.: Cienc. Agrar., v.35, p.891-900, 2014.

SOUZA, F.N.; LATORRE, A.O.; CANICEIRO, B.D. et al. Proliferação de linfócitos e apoptose de células CD25+ de bovinos infectados pelo vírus da leucose enzoótica bovina. Arq. Bras. Med. Vet. Zootec., v.63, p.1124-1130, 2011.

VAN KAMPEL, C.; MALLARD, B.A. Effects of peripartum stress and health on circulating bovine lymphocyte subsets. Vet. Immunol. Immunopathol., v.59, p.79-91, 1997. 